\title{
The Response of the Heat Affected Zone to Natural Aging in Friction Welded Al-Mg-Si-T6 Alloy
}

\author{
F.B. ABUDAIA ${ }^{a, *}$ AND K. MARWAN ${ }^{b}$ \\ ${ }^{a}$ Department of Materials and Metallurgical Engineering, Faculty of Engineering, University of Tripoli \\ Tripoli, Libya \\ ${ }^{b}$ Welding Research Center, Tajoora, Libya
}

\begin{abstract}
In this work, it is aimed to study the effect of welding parameters on the response of the fully reverted zone of the heat affected zone in $\mathrm{Al}-\mathrm{Mg}-\mathrm{Si}-\mathrm{T} 6$ alloy to natural aging. The study takes in consideration the effect of welding time which usually receives less attention than other parameters. Rods of $25 \mathrm{~mm}$ diameter were friction welded at varying welding times and forge pressures. The highest hardness recovery in the fully reverted zone was obtained by a combination of a high heat input with a short welding time. These welding conditions produced a thermal welding cycle with higher cooling rate with a relatively longer time at the peak temperature. The high cooling rate is important to avoid the formation of the non-hardening $\mathrm{Mg}_{2} \mathrm{Si}$ precipitates which do not contribute to the hardness. The longer hold time at peak temperature permits more precipitate dissolution to increase the solute concentration in the solution before the rapid cooling.
\end{abstract}

DOI: 10.12693/APhysPolA.125.208

PACS: $81.20 . \mathrm{Vj}$

\section{Introduction}

AlMgSi alloy is a medium strength aluminum alloy commonly used in structural applications. The main products of this alloy are extruded bars and tubes used in architectural applications. The alloy is a heat treatable alloy and the strengthening is attributed to the $\mathrm{Mg}_{2} \mathrm{Si}$ fine precipitates known as $\beta^{\prime \prime}$ precipitates. The balanced ratio of $\mathrm{Mg}$ and $\mathrm{Si}$ to form $\mathrm{Mg}_{2} \mathrm{Si}$ is 1.73:1, but excess $\mathrm{Si}$ may be added to promote the response to heat treatment and to precipitate Si to increase the strength.

In general, joining heat treatable aluminum alloys by welding processes cause deterioration in strength and hardness in the heat affected zone (HAZ) of welded joints. The loss in hardness is attributed either to dissolution of the hardening $\beta^{\prime \prime}$ precipitates or to the formation of the non-hardening precipitates known as $\beta^{\prime}$ precipitates. In friction welding joining occurs without melting but at the interface the temperature increases close to the melting point. Precipitate dissolution in HAZ occurs closer to the interface where the peak temperature exceeds $490^{\circ} \mathrm{C}$. Further away both reactions (precipitate dissolution and coarsening) would take place. The fully reverted zone in the HAZ which suffer complete dissolution (reversion) of the $\beta^{\prime \prime}$ precipitates would show better hardness recovery during the natural aging later on. Although post weld heat treatment can completely retrieve the hardness, it is not always feasible to carry out post weld heat treatment in addition to the extra cost of this treatment.

In this work, the response of the completely reverted zone of the HAZ for AlMgSi alloy is studied in relation to the effect of welding time and forge pressure. The effect of welding time seems to receive less attention in

* corresponding author; e-mail: Fabudaia@yahoo.com research studies of friction welding. For example Rafi et al. studied the effect of rotation speed and the forge pressure on the mechanical properties and microstructure in aluminum alloy AA7075 [1]. Ozdemir investigated the effect of rotation speed on properties and microstructure of friction-welded joints between AISI 304L and AISI 4340 [2].

\section{Experimental work}

Four joints were welded by friction welding. Each joint was made by welding of two rods $25 \mathrm{~mm}$ diameter and $200 \mathrm{~mm}$ length. The welding parameters of the four experiments and the calculated heat inputs and the heating times are given in Table I. The chemical composition of the alloy was determined using spark emission spectrometer model JY $132 \mathrm{~F}$.

TABLE I

Welding parameters and calculated heating time and heat input for all welded samples.

\begin{tabular}{c|c|c|c|c|c|c}
\hline \hline $\begin{array}{c}\text { Sample } \\
\text { No. }\end{array}$ & $\begin{array}{c}\text { Rotating } \\
\text { speed } \\
{[\mathrm{rpm}]}\end{array}$ & $\begin{array}{c}\text { Welding } \\
\text { time } \\
{[\mathrm{s}]}\end{array}$ & $\begin{array}{c}\text { Friction } \\
\text { pressure } \\
{[\mathrm{MPa}]}\end{array}$ & $\begin{array}{c}\text { Forge } \\
\text { pressure } \\
{[\mathrm{MPa}]}\end{array}$ & $\begin{array}{c}\text { Heat } \\
\text { input } \\
{\left[\mathrm{W} / \mathrm{mm}^{2}\right]}\end{array}$ & $\begin{array}{c}\text { Heating } \\
\text { time } \\
{[\mathrm{s}]}\end{array}$ \\
\hline 1 & 2500 & 1.5 & 20 & 40 & 43.6 & 0.21 \\
2 & 2500 & 3 & 20 & 40 & 43.6 & 0.21 \\
3 & 2500 & 1.5 & 30 & 60 & 65.45 & 0.09 \\
4 & 2500 & 3 & 30 & 60 & 65.45 & 0.09
\end{tabular}

Joints were welded using Thompson friction welding machine model 15 single end sliding head. Welded joints were then subjected to milling operations to produce tow parallel flat surfaces to carry out the hardness measurements. The test surfaces were ground on abrasive papers up to 1200 grit and polished. Hardness tests were carried out using microhardness tester machine Buehler-micromet 2101 using the Vickers-scale (HV) with applied load $100 \mathrm{~g}$ and a $10 \mathrm{~s}$ load time. The hardness profiles were taken from the center line of the joint $(\mathrm{CL})$ to a 
distance of $10 \mathrm{~mm}$. Hardness measurements were taken in the same day of the welding and after eight days of natural aging after welding.

\section{Results}

The chemical composition of the alloy in wt\% analyzed by spectrometer is given in Table II below. The chemical composition showed that the alloy contains excess silicon content than required to form the $\mathrm{Mg}_{2} \mathrm{Si}$ precipitates. Figure 1a,b shows a welded joint and a schematic drawing for the joint as prepared for hardness measurements. Figure $2 \mathrm{a}-\mathrm{d}$ shows hardness profiles for the four welded joints. The two profiles in each figure correspond to hardness measurements in the same day of welding and after 8 days of natural aging (NA). The hardness profiles after 8 days of aging show hardness recovery in regions adjacent to the interface in the fully reverted zones. Hardness profiles reveal the followings:

I. Very small hardness recovery was achieved in samples 2 and 4 compared with samples 1 and 3 in the fully reverted zones.

II. The highest hardness recovery in the fully reverted zone was observed in sample 3 .

III. In all test samples hardness recovery outside the fully reverted zone (in the mixed region) is very small.

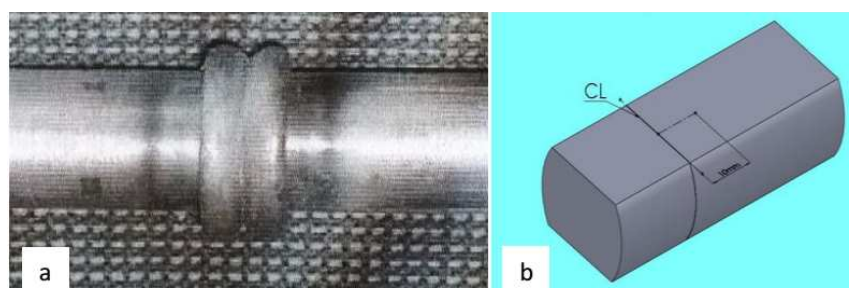

Fig. 1. (a) A welded joint and (b) an illustration of sample preparation for hardness measurements.

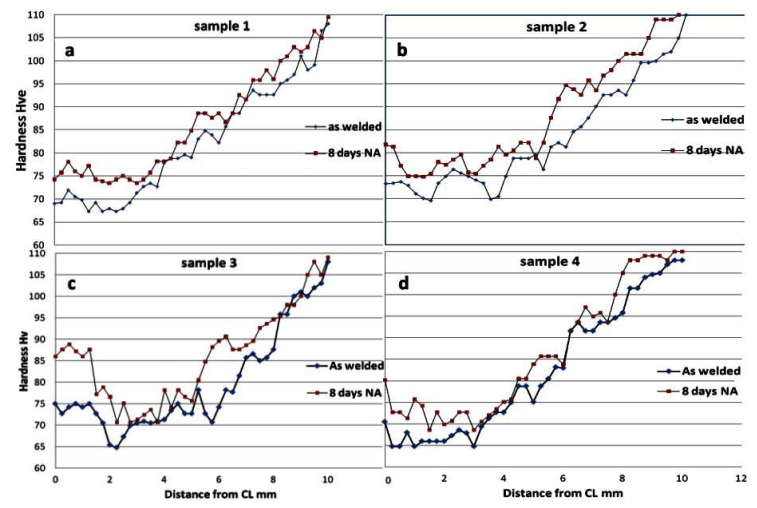

Fig. 2. (a)-(d) Hardness profiles for all welded joints immediately after welding and after 8 days of natural aging.
TABLE II

Chemical composition of the welded test samples in wt\%.

\begin{tabular}{c|c|c|c|c|c|c|c|c|c|c}
\hline \hline Element & $\mathrm{Mg}$ & $\mathrm{Si}$ & $\mathrm{Mn}$ & $\mathrm{Cu}$ & $\mathrm{Fe}$ & $\mathrm{Cr}$ & $\mathrm{Ti}$ & $\mathrm{Zn}$ & $\mathrm{Pb}$ & $\mathrm{Al}$ \\
\hline wt\% & 1.26 & 1.05 & 0.68 & 0.08 & 0.62 & 0.18 & 0.04 & 0.04 & 0.03 & balance
\end{tabular}

\section{Discussion}

In this work it is noticed that welding time in friction welding has an effect on the degree of hardness recovery of the reverted zone in the HAZ. The discussion will take this parameter in consideration in addition to the effect of the applied forge pressure.

\subsection{The thermal cycle}

Equation (1) [3] gives the theoretical variation of temperature with distance from the interface plane during the steady state period and plotted in Fig. 3 for all tested samples

$$
\begin{aligned}
T & -T_{0}=\frac{q^{0} \sqrt{t}}{A \rho c \sqrt{\pi \alpha}} \\
& \times\left[\exp \left(\frac{-z^{2}}{4 \alpha t}\right)-\left(\frac{\sqrt{\pi} z}{\sqrt{4 \alpha t}}\right) \operatorname{erfc}\left(\frac{z}{\sqrt{4 \alpha t}}\right)\right],
\end{aligned}
$$

where $T_{0}$ is the ambient temperature (in ${ }^{\circ} \mathrm{C}$ ), $q_{0} / A$ is the heat input (in $\mathrm{W} / \mathrm{mm}^{2}$ ), $\rho c$ is the is the volume heat capacity (in $\left.\mathrm{J} /\left(\mathrm{mm}^{3}{ }^{\circ} \mathrm{C}\right)\right), \alpha$ is the thermal diffusivity (in $\mathrm{mm}^{2} / \mathrm{s}$ ), $z$ is the distance from the interface plane (in $\mathrm{mm}$ ), $t$ is the time (in s) and $\operatorname{erfc}(u)$ is the complementary error function.

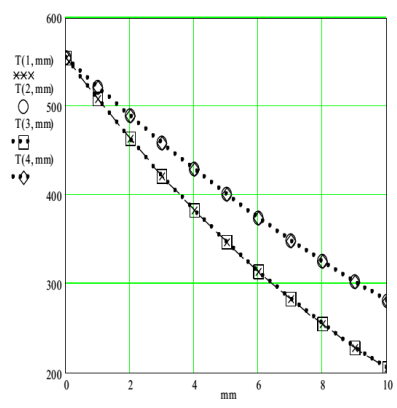

Fig. 3. Calculated temperature distribution in samples 1, 2, 3 and 4 from the interface up to $10 \mathrm{~mm}$ depth in welded joints.

Knowing that the dissolution temperature of the $\beta^{\prime \prime}$ is about $490^{\circ} \mathrm{C}$, accordingly from Fig. 3 the widths of the completely reverted zones should be about $1.5 \mathrm{~mm}$ in samples 1 and 3 and $2 \mathrm{~mm}$ in samples 2 and 4 . Thus the maximum hardness recovery is expected to occur within these depths. Beyond the fully reverted zone, the fraction of the dissolved $\beta^{\prime \prime}$ precipitates is continuously decreasing with distance and particle coarsening is taking place by formation of the non-hardening $\beta^{\prime}$ precipitates. Outside the region of fully reverted zone the loss of hardness is lower but the potential for re-precipitation of $\beta^{\prime \prime}$ precipitates and hardness recovery is also lower. 
The thermal welding cycle (heating and cooling rates and the retention time at peak temperature) depends on the heat input and the total welding time. So the heating time $\left(t_{\mathrm{h}}\right.$ in $\left.\mathrm{s}\right)$ to reach the peak temperature $T_{\max }$ and the steady state time at peak temperature will consequently depend on the applied pressure, the rotating speed and the welding time. The peak temperature attained is $555^{\circ} \mathrm{C}$ which is below the melting point. The required heating time to reach the peak temperature is inversely related to the heat input according to Eq. (2) [3] and values of $t_{\mathrm{h}}$ are indicated in Table I:

$$
t_{\mathrm{h}}=\left[\frac{\left(T_{\max }-T^{0}\right) \rho c \sqrt{\pi \alpha}}{\left(q_{0} / A\right)}\right]^{2} .
$$

The steady state time at the peak temperature equals the total welding time minus the heating time. Welded joints then cool down at rates controlled by the welding parameters. The applied welding conditions had produced identical cooling curves for samples 1 and 3 and identical cooling curves for samples 2 and 4 .

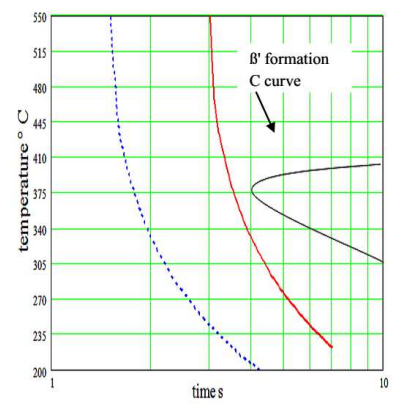

Fig. 4. Cooling curves for samples 1 and 3 (dot line) and samples 2 and 4 (solid line).

Figure 4 shows the cooling curves at the interface for the four welded joints and they were super imposed on the $C$-curve for formation of $\beta^{\prime}$ precipitates for the aluminum alloy AA6082. Cooling curves were calculated according to Eq. (3) [3] where $t_{\mathrm{s}}$ is the total welding time (in s)

$$
\begin{aligned}
T & -T_{0}=\frac{q_{0} \sqrt{t_{\mathrm{h}} / t_{\mathrm{s}}}}{A \rho c \sqrt{\pi \alpha}}\left\{\sqrt { t } \left[\exp \left(\frac{-z^{2}}{4 \alpha t}\right)-\left(\frac{\sqrt{\pi} z}{\sqrt{4 \alpha t}}\right)\right.\right. \\
& \left.\times \operatorname{erfc}\left(\frac{z}{\sqrt{4 \alpha t}}\right)\right]-\sqrt{\left(t-t_{\mathrm{s}}\right)}\left[\exp \left(\frac{-z^{2}}{4 \alpha\left(t-t_{\mathrm{s}}\right)}\right)\right. \\
& \left.\left.-\left(\frac{\sqrt{\pi} z}{\sqrt{4 \alpha\left(t-t_{\mathrm{s}}\right)}}\right) \operatorname{erfc}\left(\frac{z}{\sqrt{4 \alpha\left(t-t_{\mathrm{s}}\right)}}\right)\right]\right\} .
\end{aligned}
$$

\subsection{Response to natural aging}

The weak response to natural aging of samples 2 and 4 (in the fully reverted zone) could be attributed to the combined contribution from the thermal cycle and the chemical composition of the alloy. Examining the $C$ curve for the alloy AA6082 for precipitation of $\beta^{\prime}\left(\mathrm{Mg}_{2} \mathrm{Si}\right)$ showed that the cooling cycle would just avoid the precipitation of the non-hardening metastable $\beta^{\prime}$. But the nose of the $C$ curve for the alloy in this work would be shifted to a shorter time compared with the alloy 6082 due to the effect of the excess silicon in this alloy which promote precipitation of the non-hardening metastable $\beta^{\prime}$ precipitates. With more $\beta^{\prime}$ precipitates formed, the solute concentrations in the solution become smaller and the amount of the $\beta^{\prime \prime}$ to precipitate during the natural aging and the hardness recovery is decreased. For samples 1 and 3 the cooling rate is high enough to avoid precipitation of $\beta^{\prime}$ and thus resulted in the state of supersaturation which eventually would precipitate the hardening metastable $\beta^{\prime \prime}$ precipitates responsible for hardness recovery.

\subsection{Welding time}

The heating rate for sample 3 is higher than for sample 1. As shown in Table I, the heating time for sample 3 is shorter than for sample 1 . The total time of welding in these two experiments were the same and was $1.5 \mathrm{~s}$. The steady state time is therefore for sample 1 at the peak temperature less than available to sample 3 . Particle dissolution at high temperature occurs over a time interval. The fraction of dissolved precipitate $(f)$ is related to the retention time $(t)$ (in s) according to Eq. (4) [4]. More retention time will cause more dissolution of precipitate and would increase the solute concentration in the solution

$$
f=\left[\frac{t}{t_{1}}\right]^{n}
$$

where $t_{1}$ is the maximum hold time (in s) required for complete dissolution of $\beta^{\prime \prime}$ precipitates and $n \leq 0.5$ (for alloy $6082 t_{1}$ is $2.95 \mathrm{~s}$ - see Ref. [4] for details. As sample 3 had experienced more time at the peak temperature, this would increase the concentration of the solute in the solution and will increase the precipitation of the hardening $\beta^{\prime \prime}$ precipitates and the hardness recovery later on during the natural aging.

\section{Conclusions}

Maximum hardness recovery in the fully reverted zone of the HAZ is obtained by a combination of a high heat input with a short welding time. This is to increase the cooling rate to avoid precipitation of the non-hardening precipitates and to maximize solute concentration at peak temperature.

\section{Acknowledgments}

The authors wish to thank the Welding Research Center at Tojora, Libya for the support.

\section{References}

[1] H.K. Rafi, G.D. Janaki Ram, G. Phanikumar, K. Prasad Rao, Mater. Design 31, 2375 (2010).

[2] N. Ozdemir, Mater. Lett. 59, 2504 (2005).

[3] O.T. Midling, O.A. Grong, Acta Metal. Mater. 42, 1595 (1994).

[4] O.R. Myhr, O. Grong, Acta Metal. Mater. 39, 2693 (1991). 